
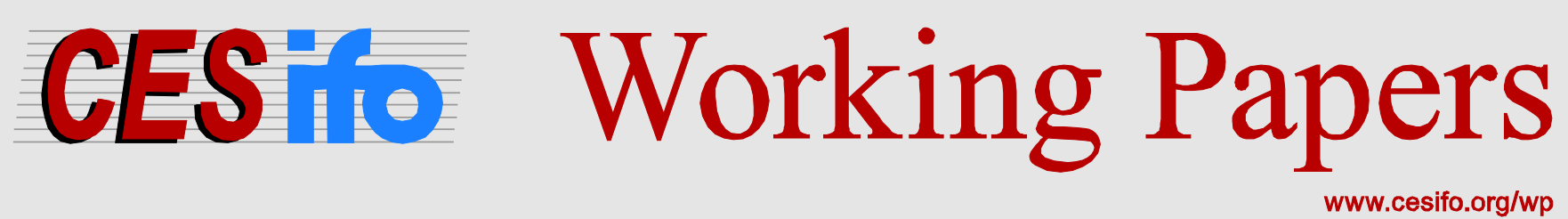

\title{
To Work or not to Work? \\ The Effect of Child-Care Subsidies on the Labour Supply of Parents
}

\section{Tuomas Kosonen}

\section{CESIFO WORKING PAPER NO. 4065 \\ CATEGORY 4: LABOUR MARKETS \\ JANUARY 2013}
An electronic version of the paper may be downloaded
- from the SSRN website: Www.SSRN.com
- from the RePEc website: Www.RePEc.org
- from the CESifo website: www.CESifo-group.org/wp

\section{CESifo}




\title{
To Work or not to Work? The Effect of Child-Care Subsidies on the Labour Supply of Parents
}

\begin{abstract}
This paper studies the effect of child-care subsidies on parental labour supply. I use variation arising from changes in the municipality-specific supplement to Finnish child homecare allowance to identify the causal effect of subsidies on the labour force participation of parents. The variation in labour supply incentives is plausibly exogenous, since eligibility depends on municipal-level rules, but not on family income. Robustness checks indicate that the results are not driven by policy endogeneity or residential sorting. I find a robust result that 100 euros higher supplement per month reduces the maternal labour supply by 3 per cent.
\end{abstract}

JEL-Code: J220, J130, H220.

Keywords: parental labour supply, child-care subsidies, participation elasticity.

Tuomas Kosonen

Government Institute of Economic Research (VATT)

Arkadiankatu 7, P.O.Box 1279

Finland - 00101 Helsinki

tuomas.kosonen@vatt.fi

$7^{\text {th }}$ January 2013

I would like to thank Saku Aura, Richard Blundell, Wojciech Kopczuk, Jukka Pirttilä, Eva Mörk and Roope Uusitalo, as well as many seminar participants for their helpful comments. I am also grateful for the financial support of the Yrjö Jahnsson Foundation, the Finnish Cultural Foundation and Palkansaajasäätiö for costs arising from a visit to University College London. 


\section{Introduction}

A key question faced by most industrialized countries concerns policy measures aimed at increasing labour supply. With ageing populations, a smaller workforce will have to provide for a larger retired share of the population. At the same time it has proved difficult to extend working lives through changes in retirement policies (Lindbeck and Persson 2003 and OECD 2009). This has led to increased attention towards the study of labour supply decisions in different phases of working age. One important gap in working lives occurs when parents have children. Mothers in particular may not participate in the labour force for many years after they give birth.

This paper studies the impact of child-care subsidies on parental labour supply. In the Finnish day-care system, a relatively generous home-care allowance is given to parents who stay at home to take care of their children. This subsidy clearly increases incentives to stay outside of the labour force for prolonged periods. Changes in a municipal supplement to this allowance provide exogenous variation in the labour supply incentives of parents, because they do not depend on family income. A parent is eligible for a supplement based on the municipality he or she lives in and the age of his or her youngest child. The amount of supplement one is eligible for is usually fixed amount of on average 150 euros per month.

For welfare implications it is important to know how these rather strong incentives to stay outside of the labour force for prolonged periods really affects parents. The main results show that increasing the supplement has significant negative labour supply and earned income effects on mothers. The estimated effect indicates that 3 per cent fewer mothers participate to the labour force when a supplement is increased by 100 euros per month. I study the labour force participation of fathers as well, but do not find any effect on their labour supply.

A municipal supplement to the home-care allowance provides a good case of a regional experimental set-up. There is a rich variation of supplement policies that are reformed over time, and are fully observed. There are no other regionally varying policies that affect the labour supply of parents of young children in Finland. However, there remains a worry that the supplement policy could in some way depend on economic conditions of the municipality providing it and therefore on the aggregate labour supply of parents. On the contrary, the main results are reliable because they survive a battery of robustness checks. Figures 1 and 2 present graphically the 
Figure 1: Visual presentation of DD approach on mothers' earned income
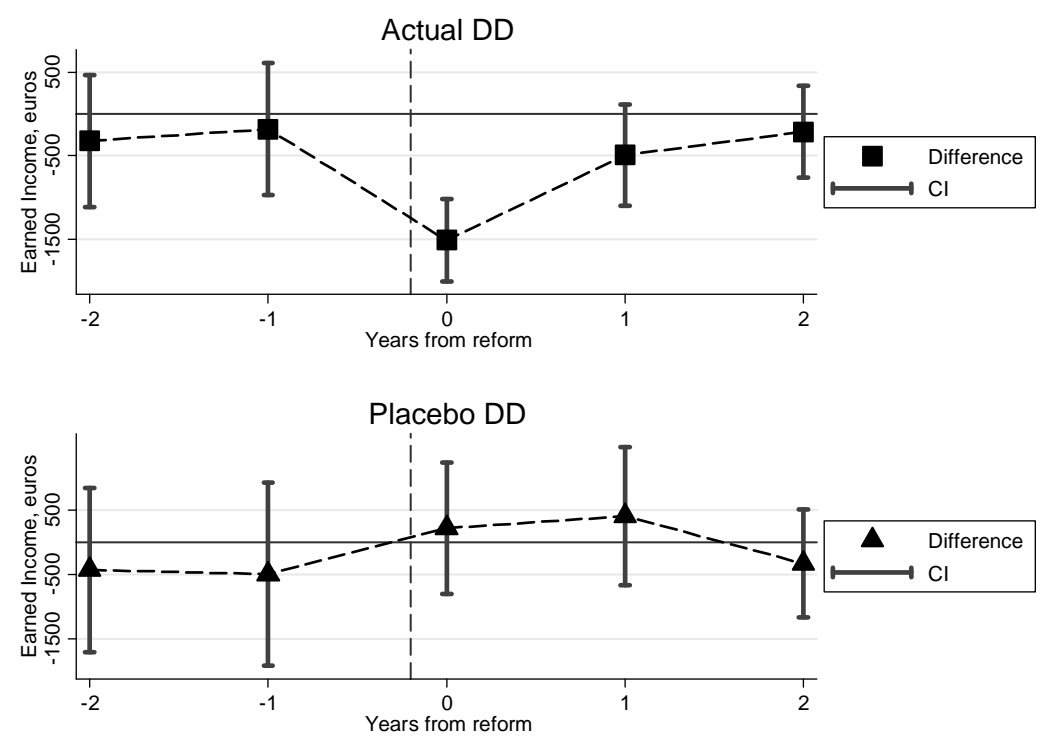

Note: Top panel presents lags and leads of DD coefficient on mothers whose youngest child is between 9 months and 3 years old from regression that is similar to main estimates. Bottom panel presents similar coefficients performed on main placebo group: mothers whose youngest child is between 3 and 5 years old.

main robustness evidence. They show a clear negative impact from increasing the supplement on the earnings and labour supply of treated parents compared to parents in control municipalities, but no difference prior to the reform. Furthermore, the parents of slightly older than eligible children are not affected by the reforms in the same municipalities. Also econometric evidence shows that other background variables are not correlated with the reforms, which would indicate policy endogeneity.

This study contributes to a growing literature on how child-care policies affect the labour force participation of parents. Firstly there is a literature studying policies that are targeted at the working poor or low-income families. Overall the Earned Income Tax Credit (EITC) policy in the USA, the Canadian National Child Benefit (CNBC) program and the Working Families Tax Credit (WFTC) in the UK increased participation incentives mostly for the working poor and single parent households. Parents respond to these programs mainly along the extensive margin: they participate to labour force more (Eissa and Liebman 1996 and Eissa and Hoynes 2004 for EITC, Milligan and Stabile 2007 for CNBC and Blundell et al. 2000 and Brewer et 
Figure 2: Visual presentation of DD approach on mothers' participation
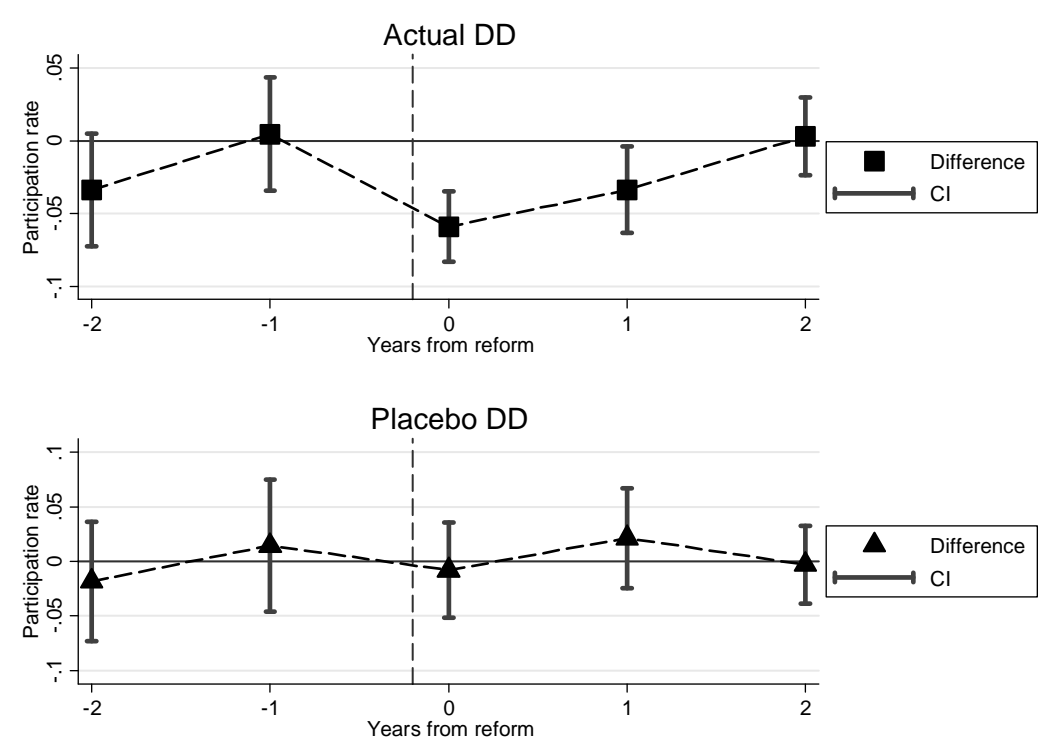

Note: Top panel presents lags and leads of DD coefficient on mothers whose youngest child is between 9 months and 3 years old from regression that is similar to main estimates. Bottom panel presents similar coefficients performed on main placebo group: mothers whose youngest child is between 3 and 5 years old.

al. 2006 for WFTC). All these programs were increasing labour force participation incentives of groups which labour force participation rate was not very high prior to the program initiative.

Secondly there are programs where the price of child care was reduced or it was made more readily available. The evidence from these is mixed. In the Nordic countries it seems that the expansion of child care (Havnes and Mogstad 2011a) or reduction of it's price (Lundin et al. 2008) does not affect parents' participation to the labour force. However, Canadian evidence shows that both lower day care price (Baker et al. 2008a) increases parents' and especially mothers' labour force participation. This differing evidence could be explained by the fact that in the Nordic countries mothers' labour force participation was already on a quite high level, as opposed to Canada. Thus, participation is increased only when it was not already on a high level.

The above mentioned papers studied programs that increase incentives to participate to labour force. Two papers study the Cash-For-Care (CFC) reform in Norway: Naz 2004 and Schone 2004. The CFC reduces the incentives to supply labour, since it is a subsidy for parents 
who do not place their children to the publicly provided day care. Both papers find that the CFC reduced labour force participation of mothers. This finding is in line with the current paper. The home care allowance system studied here focuses even more closely to the participation margin, since it is only received when a parent is staying at home taking care for the children. It does not apply for private care, as the CFC does. Thus the incentive to stay outside of the labour force is even stronger. This explains the larger response from mothers found here than from the CFC reform. I also find that higher educated respond more than medium educated, same what Naz (2004) finds from the CFC reform.

This paper also contributes by carefully estimating a participation elasticity. This estimation is facilitated by the fact that home care allowance affects potentially every parents' labour force participation incentives as opposed to for example EITC or CNCB that apply to poorer families. I calculate two income measures corresponding to situations when a parent is in work and when not in work. The difference of these measures are estimated against participation decisions. Municipal supplements are instruments in this estimation. The results imply a participation elasticy of 0.8 . It seems that targeting incentives strongly against participating to labour force produces high participation elasticities, as I found here.

The rest of the paper proceeds as follows. In section 2, I present the source of variation in the child-care subsidies. I also provide a short description of the Finnish child-care system. The identification issues and the econometric specification are discussed in section 3. Section 4, describes the data-set and shows statistics derived from it. The estimation results and some robustness checks are given in section 5 . I discuss the economic interpretation of the results and estimate participation elasticity in section 6 . The last section concludes the study. The appendix A presents further robustness checks.

\section{Forms of child care}

Child care can be structured in many ways. To understand the particular features of the Finnish institutions, I first compare these to arrangements in other countries. I then describe the Finnish day-care system in more detail and discuss how the institutions result in exogenous variation in the parents' incentives to supply labour. 


\section{How is Finland doing compared with other countries?}

The Nordic countries provide extensive public day care, subsidized private day care and parental leave policies. Children are entitled to a place in a public day-care centre. The price for day care is heavily subsidized by the government. In Anglo-Saxon and central European countries day care relies more on private providers. The price a household ends up paying for day care can be much higher than in the Nordic countries. Parental leave policies are provided in the Nordic countries for parents whose youngest child is under one year old (with some national variation). This is much more than in the other OECD countries in general. In Finland, after the parental leave, the home-care allowance continues for as long as two years. The home-care allowance works in a similar way to parental leave: one has the right to return to one's previous work place after the leave and there is a subsidy from the government to the parent.

A key feature that countries try to influence through their child-care institutions is the employment rate of mothers. Figure 3 presents maternal employment rates by the age of the youngest child in selected countries in 2005. It is evident that the Nordic countries have higher employment rates than the OECD countries on average. Further, the equality between sexes has been the focus or parental leave reforms. Despite of this, in Finland it is still relatively rear that a father stays at home for years to take care of his children.

Figure 3: The employment rate of mothers by the age of the youngest child. Source: OECD (2007)

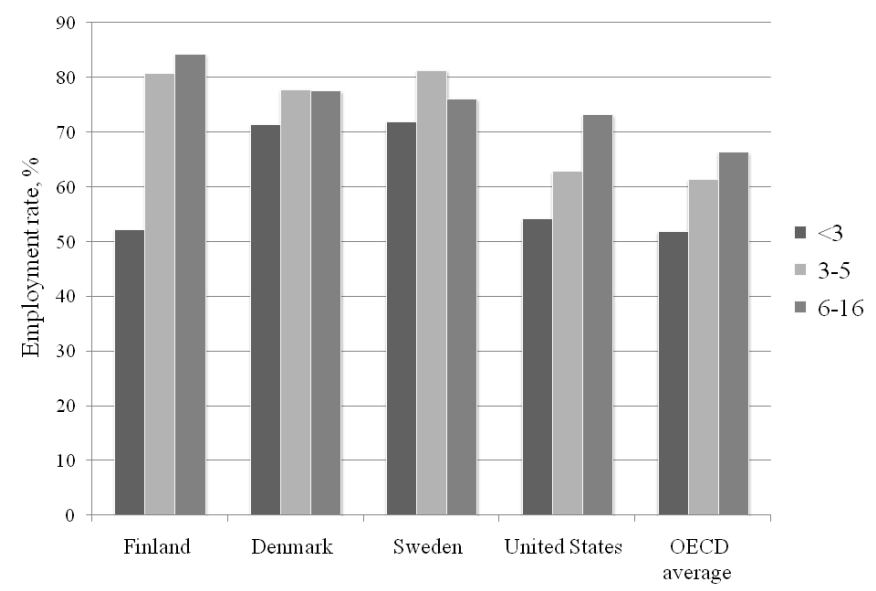


The first column in figure 3 shows the employment rate of mothers whose youngest child is under 3 years old. This column stands out for Finland even compared to the other Nordic countries. In contrast to Sweden and Denmark, Finland provides a home-care allowance for this group. I hypothesize that the Finnish home-care allowance system has an effect on the labour supply of parents. When mothers are no longer eligible for this allowance, their employment rate shoots back to the high level seen in the other columns in figure 3 .

\section{Finnish day care}

The idea of the Finnish child-care system has been to provide financial assistance to parents regardless of the choice a parent makes. After maternity leave (when the newborn child is 10 months old), parents can choose essentially between three child-care alternatives, all of which are financially subsidized by the government: home care, public day care or private day care.

When a young child is cared for by a parent, he or she is entitled to the child home-care allowance (HCA). Every child is eligible for this allowance who is not in public or private day care and is between 9 months and 3 years old. The amount a family is eligible for depends on the family's characteristics and is from 300 to 500 euros per month. The child home-care allowance may be paid to either parent, although it is predominantly the mother who takes up the allowance. If a parent receives the HCA, the same family can't receive other forms of child care support (public or private day care) for the same child. Thus this feature rules out the use of HCA for financing private day care. ${ }^{1}$ A parent taking up HCA can, after the HCA period ends, return to the same job that he or she left from.

A municipal supplement to the HCA constitutes the interesting variation in this study. Some municipalities pay a supplement on top of the national HCA while other municipalities have no supplement policy. There is a rich variation in the details of how each municipality pays its supplement, and these rules are fully observed. Municipalities occasionally change their supplement rules. This creates variation in the labour force participation incentives for parents that are otherwise similar.

It is possible to receive an extra supplement if there are older siblings in the family. The supplement is on average 200 euros per month and child and the sibling-extra supplement is

\footnotetext{
${ }^{1}$ Which is supported by a different allowance, private-care allowance.
} 
on average 50 euros per family. With the exception of a few municipalities, the municipal supplement does not depend on family income. There is also a prior-work condition in some smaller municipalities, according to which to be entitled to the municipal supplement the parent must have worked prior to the parental leave.

The municipal supplement system has been part of the Finnish child-care system since the 1980's. In this study, the observation period reaches from 1995 to 2005. Over this period, there were around 450 municipalities in Finland. Five of them had adopted a supplement policy in 1995 and the figure had increased to 65 by 2005. Figure 4 shows how the municipal supplement has spread over time. ${ }^{2}$

Figure 4: Maps of Finland showing municipalities having a supplement policy in years 1995, 1998, 2001 and 2005 respectively.

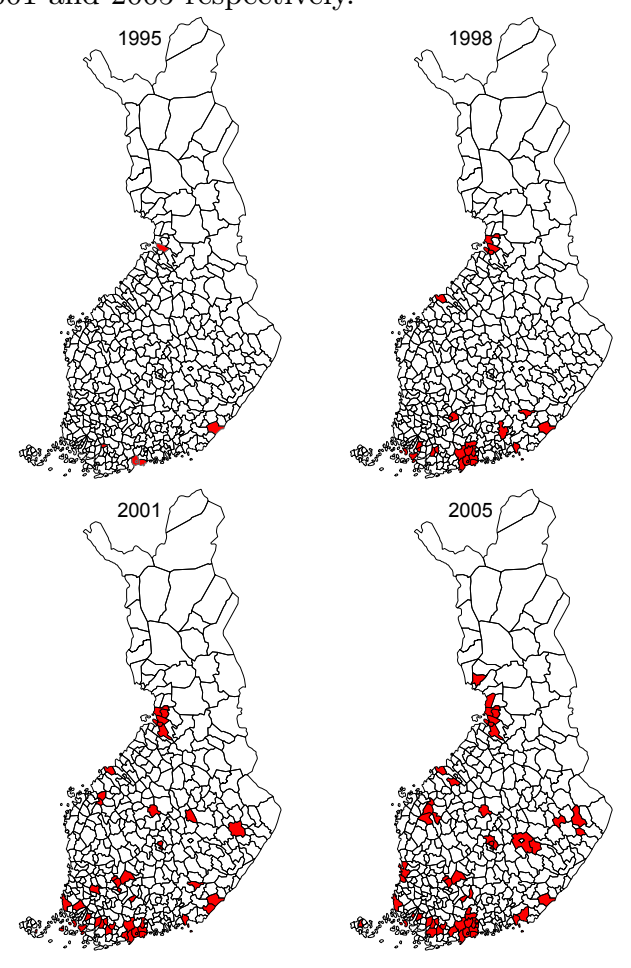

Public day care is the predominant choice of day care in Finland for a typical family. Every child under the age of 7 (when they start primary school) is entitled to a public day-care place if they request it. ${ }^{3}$ A child can be placed in public day care even if neither of the parents are in

\footnotetext{
${ }^{2}$ There are cities among both supplement and no supplement municipalities. However, supplement municipalities are on average more populous.

${ }^{3}$ This is stated in legislation. Before 1995 the law stated that every child under the age of 4 is entitled to
} 
work. Day-care fees are regulated by the government. A typical family with two children paid 380 euros per month in 2005 for a place in public day care.

Private day care is also subsidized. ${ }^{4}$ Furthermore, municipalities are able to pay a municipal supplement on top of the private day-care allowance if they choose to. Majority of tax revenue is collected by central government and a part of tax revenue is collected by municipalities directly. This study focuses on the employment effect of the home-care allowance and a supplement to it. Thus, the question of interest is not whether a family chooses private or public day care since these two choices are similar in terms of the employment decision.

An employed parent faces different fee and subsidy schemes than a non-employed parent. A formula below describes how different fees and subsidies affect parental income when a parent is employed $\left(I_{\text {work }}\right)$ and when not $\left(I_{\text {Notwork }}\right)$ :

$$
\begin{gathered}
I_{\text {work }}=\operatorname{Earned}(I)-D C(I) \\
I_{\text {Notwork }}=H C A(I) * 1(\text { chage }<3)+S * 1(m=1, \text { chage }<3, \text { other })
\end{gathered}
$$

where Earned refers to earned income net of tax, $D C$ to day care fees, $H C A$ to home-care allowance and $S$ to supplement to it. In parentheses there are variables that affect these: $m=1$ refers to municipalities that have the supplement policy, chage to the age of the youngest child in household and other to the fact that municipal supplements depend on other non-income related characteristics. The $I$ in parentheses indicates that the fee or subsidy in question is a function of personal or family income. Therefore this formula highlights the fact that eligibility for an amount $S$ of the municipal supplement depends on whether the municipality has the supplement and on more specific municipal level rules, but not on income (in most municipalities ${ }^{5}$ ).

\footnotetext{
public day care.

${ }^{4}$ This system has been in place nationwide since 1997. Between 1995 and 1997 there was an experiment in 33 municipalities that provided a similar allowance. Viitanen (2007) describes this experiment in detail. She found a positive effect on the use of private day care, but little effect on labour force participation.

${ }^{5}$ In the empirical analysis the results are not sensitive to excluding the few municipalities where the amount of supplement depends on family income
} 


\section{Identification and econometric strategy}

To estimate the effect of a municipal supplement on maternal outcomes, I apply a natural experimental approach, a difference-in-differences (DD) with continuous treatment. To further explore the validity of identification, I extend this to a triple difference approach (DDD) in some parts of the analysis. In the DD strategy I compare outcomes for mothers living in different municipalities before and after there was a change in the supplement policy. Mothers living in a municipality that did not change the amount of supplement policy it provides comprise the control group. The supplement policy is measured as the actual supplement a mother is eligible for based on her observable characteristics. Thus it is not a dummy variable as in the basic DD approach. The model is estimated for mothers with children in the home-care allowance eligible age, when the child is between 9 months and under 3 years old. In the triple-difference estimation the third difference is whether or not the youngest child is under 3 years old. This distinction is meaningful, since a child is no longer eligible for supplement when he or she turns three years of age. I estimate the OLS equation:

$$
Y_{i y m}=\alpha+\beta_{1} P_{i y m}+\beta_{2} X_{i y m}+\beta_{3} M_{u n}+\beta_{4} \text { Year }_{y}+\varepsilon_{i y m}
$$

The dependent variable is either labour supply indicator or earned income in euros, $Y$. For labour supply $Y$ takes a value 1 when a parent participates and zero otherwise. The key explanatory variable is eligibility for $P$ euros of municipal supplement. The model identifies $\beta_{1}$, the effect of a subsidy $P_{i y m}$ on labour supply $Y_{i y m}$ in year $y$, municipality $m$ and for individual $i$. In the case of labour supply, $\beta_{1}$ shows the change in probability of a parent supplying labour when $P$ is increased by one unit. The other variables in equation (3) are the municipal $\left(M u n_{m}\right)$ and year $\left(Y_{e a r}\right)$ dummies and a control vector $\left(X_{i y m}\right)$. In DD estimations the control vector includes husbands' income, age, age squared, dummies for the level of education, municipal unemployment rate, the number of women in municipality and the costs of day care in municipality. When estimating the triple difference, the control vector includes the interaction terms of the dummies used in the DD approach, most importantly municipality by year dummies, which is not possible in DD.

Changes in a municipality's supplement rules depend on the age of the youngest child. In 
some cases the upper age limit for eligibility is raised gradually from 1 year and 2 months to 2 years. A mother's decision to return to work is correlated with the age of the youngest child. Consequently, $\beta_{1}$ would be biased away from zero if this correlation were not taken into account. To control for this variation in a flexible way, I included dummies for the age of the youngest child. In the main estimates, a dummy for each 3 months of age of the youngest child controls for all the unwanted correlation between policy rules and child's age. Other specifications for the length of the age interval in the dummy produce similar results as in the main estimates.

\section{Identification issues}

The DD approach identifies a causal effect of the municipal supplement on outcome $Y$ provided that the standard DD assumption holds: selection into treatment should be exogenous to outcome. In particular, the model identifies $\beta_{1}$ conditional on controls provided that the following holds:

$$
E\left[Y_{\text {iym }}^{0} \mid m, y, P_{\text {iym }}, X_{i y m}\right]=E\left[Y_{i y m}^{0} \mid m, y, X_{i y m}\right]=\delta_{m}+\lambda_{y}+\beta_{1} X_{i y m}
$$

where I note the outcome of the control group by $Y_{i y m}^{0}$. The assumption that guarantees the identification here is that $P_{\text {iym }}$ (eligibility to supplement) is exogenous to $Y_{\text {iym }}^{0}$ (labour supply). In the basic DD case the average employment time trends need to be parallel between the treatment and control groups. To test against this, I include a linear time trend for the treatment group and municipal by year indicators in the triple difference approach into the control vector $X_{i y m}$ without any significant effect to the results. The assumption of general time trends is also tested after the main estimation results with a placebo test by estimating the DD regression for a group of mothers having older children that are not any more eligible for the supplement.

Selection into treatment is another potential problem for identification. Parents already having a child of eligible age and living in a municipality cannot self select into treatment, since the eligibility is determined by municipal level rules. However, one type of selection would be that changes in a supplement induce mothers to be more fertile. It seems unlikely that changes in fertility is a problem from the identification point if view, since a change in supplement affects labour supply incentives during current year. In contrast, increased fertility in response 
to home care allowance increases would lead to selection into treatment group two years from the change in supplement. In line of this argument, a robustness check below indicates that fertility is not causing selection problems. Finally, another potential selection problem occurs if parents move from one municipality to another based on changes in supplement policy. This is unlikely since there are fixed costs to moving outweighing potential gains from extra supplement, and furthermore spouses are tied to their current job. After the estimation results, I present some robustness checks that indicate that these selection mechanisms do not pose a threat for identification. Specifically, I run regressions on probability of ending up in the sample against changes in the municipal supplement rules. Comfortingly, this estimation produces zero effect.

The problems of inconsistent standard errors are potentially a problem in the natural experimental set ups. Bertrand et al. (2004) show that potential problems with inconsistent standard errors are less severe if there are many treated and control groups and the reforms are implemented at different points of time. One virtue of analysing the reforms in municipal supplements is that there are over 400 municipalities, 65 of which had supplement policies in 2005, contributing to multiple treatment groups. In addition, the reforms were implemented at different points of time. To further minimize these problems, I use robust standard errors throughout clustered at municipal level.

\section{Policy endogeneity}

One potential problem here is policy endogeneity, as discussed by Card and Levine (2000) and Lalive and Zweimuller (2004). The main worry is that a shock to municipal economy leads to a change in supplement rules. For instance, if a municipality reacts to a recession by increasing the supplement, it might appear that the supplement has an effect on, say, employment, when in reality there is no causal effect. The changes in municipal supplement rules would be correlated with parental labour supply if the changes in the rule were a response to shock to macro shocks like changes in municipal employment or fertility situation or the financial standing of municipality. These kind of shocks are associated changes with employment conditions and thus would be create a link with the supplement and parental labour supply changes.

As to why municipalities want to implement supplement policies, it seems the main reasons are attempting to reduce the number of children in public day care and having an image of 
child-friendly municipality. On the contrary, the reason to implement a supplement policy is not to reduce parental employment. However, some municipalities might implement policies for reasons that are indirectly related to employment. Therefore, as a further evidence against policy endogeneity hypothesis, I describe below how municipal level data behaves prior to implementing a supplement policy. The main evidence against policy endogeneity is presented in figure 1 . The figure shows that treated mothers, compared to mothers in the control group, respond to changes in the municipal supplement, but there is no such difference prior to the reforms. The figure also shows that the employment of mothers of older than eligible children in the same municipalities at the time of the reforms do not deviate from the comparable control group.

To further investigate whether there are macro shocks to municipal economy at the time of implementing changes to the supplement rules, I estimate equations for variables potentially indicating that a macro shock has occurred against implementation of municipal supplement. The regression includes leads and lags of the implementation variable. Figure 5 and table 1 presents coefficients from a fixed-effects regression on municipal-level data where indicator for implementation of supplement to the home care allowance (1(implem)) explains number of dependent variables $\left(Y_{t m}\right)$ in year $t$ and municipality $m$. The regression model used is:

$$
\begin{aligned}
Y_{t m}= & \alpha_{m}+\beta_{-2} 1\left(\text { implem }_{t-2, m}\right)+\beta_{-1} 1\left(\text { implem }_{t-1, m}\right)+\beta_{0} 1\left(\text { implem }_{t, m}\right) \\
& +\beta_{1} 1\left(\text { implem }_{t+1, m}\right)+\beta_{2} 1\left(\text { implem }_{t+2, m}\right)+X_{t m}^{\prime} \zeta+\epsilon_{t m}
\end{aligned}
$$

I have included two leads and two lags of the implementation indicator variable (1(implem it-2,m $\left._{t}\right)$ - $1\left(\right.$ implem $\left.\left._{t+2, m}\right)\right)$ and year fixed effects and in applicable cases the number of children as a covariate $\left(X_{t m}^{\prime}\right)$. Shocks to the background dependent variables prior to implementation of the supplement would be evidence of policy endogeneity. 
Figure 5: Leads and lags of an indicator for implementation of a supplement to home care allowance.

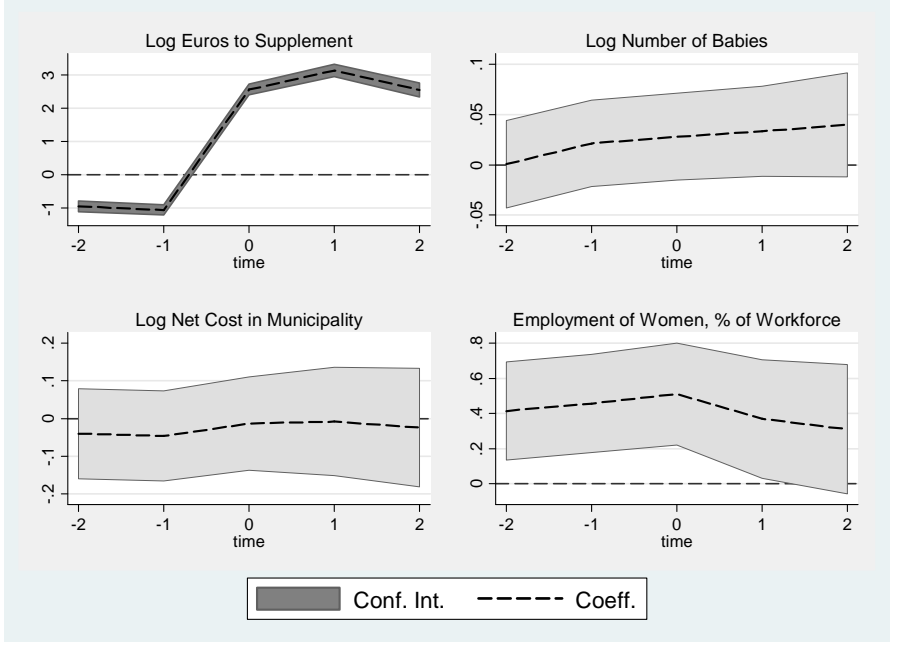

Note: First dependent variable, log euros to supplement describes take-up of the policy, next three are background variables: log number of babies describes fertility, log net costs relates to public sector expenses and employment of women shows how good are the labour markets for women in a municipality.

Table 1: Leads and lags of municipality implementing the supplement

\begin{tabular}{ccccccc}
\hline & $(1)$ & $(2)$ & $(3)$ & $(4)$ & $(5)$ & $(6)$ \\
VARS & Supplem. & CareCost & Priv.care & Homecare & Empl. & Migrate \\
\hline implem.-2 & $-0.95^{* * *}$ & 0.017 & -0.068 & 0.0033 & $0.0065^{* *}$ & -0.005 \\
& $(0.08)$ & $(0.022)$ & $(0.069)$ & $(0.013)$ & $(0.0033)$ & $(0.028)$ \\
implem.-1 & $-1.06^{* * *}$ & 0.018 & -0.103 & -0.0084 & $0.0069^{* *}$ & -0.015 \\
& $(0.08)$ & $(0.022)$ & $(0.069)$ & $(0.013)$ & $(0.0033)$ & $(0.031)$ \\
implem. & $2.56^{* * *}$ & 0.005 & -0.07 & $6.6 \mathrm{e}-05$ & $0.0109^{* * *}$ & -0.023 \\
& $(0.08)$ & $(0.021)$ & $(0.07)$ & $(0.013)$ & $(0.0034)$ & $(0.036)$ \\
implem. +1 & $3.14^{* * *}$ & -0.004 & $-0.162^{* *}$ & $0.0244^{*}$ & $0.0076^{*}$ & -0.021 \\
& $(0.1)$ & $(0.022)$ & $(0.079)$ & $(0.0145)$ & $(0.004)$ & $(0.036)$ \\
implem. +2 & $2.54^{* * *}$ & 0.014 & -0.039 & 0.0182 & 0.0066 & -0.042 \\
& $(0.11)$ & $(0.025)$ & $(0.086)$ & $(0.0157)$ & $(0.0044)$ & $(0.041)$ \\
Constant & $-5.96^{* * *}$ & $5.22^{* * *}$ & $-3.86^{* * *}$ & $-1.17 * * *$ & $3.58^{* * *}$ & $3.34^{* * *}$ \\
& $(0.51)$ & $(0.13)$ & $(0.55)$ & $(0.1)$ & $(0.00)$ & $(0.187)$ \\
$\mathrm{N}$ & 4057 & 4173 & 3406 & 3406 & 4494 & 3430 \\
$R^{2}$ & 0.49 & 0.18 & 0.06 & 0.64 & 0.8 & 0.26 \\
$\mathrm{~N}$ of Mun & 290 & 321 & 319 & 319 & 321 & 312 \\
\hline \multirow{7}{*}{ Standard errors in parentheses } & & & \\
\hline
\end{tabular}

The first estimations in figure 5 and table 1 are the amount of resources in euros municipalities 
uses for the supplement. The idea of this estimation is to show that there really is take-up when supplement policies are implemented. Municipalities would not spend any euros to fund supplement policies if the take-up was zero after it was implemented. In addition, figure 5 shows results for three other variables that are relevant from the policy endogeneity point of view: number of babies (aged 0 or 1 years), net total costs of public sector activities and the employment rate of women in municipality. The important fact to take away from the figure is that there is no significant variation in coefficients of leads and lags of the implementation variable. Stable coefficients indicate that a municipal supplement was not implemented in response to a sudden change in economic conditions described by these three outcomes.

Table 1 shows leads and lags from regressions with other dependent variables: in column (2) the cost of child care to municipality in log euros, in column (3) the logarithm of the number of children in private care, in column (4) the logarithm of the number of children receiving the home care allowance, in column (5) the employment rate and in column (6) the logarithm of migration to a municipality. The evidence against policy endogeneity in these results is that there does not seem to be significant variation in coefficients prior to implementation of the supplement. Moreover the take-up of home-care allowance and use of private day care go to the correct direction after the implementation of supplement policy.

\section{Data and descriptive statistics}

The main data set in this study is individual-level micro data for the years 1994 to 2005 . The data come from multiple sources. The base data, Income Distribution Statistics (IDS), come from Statistics Finland and are individual-level data. This data set is a repeated cross section, a stratified random sample from a population of about 5 million Finns containing over 25,000 observations from about 10,000 households per year. On top of cross section there is a rotating panel in the data that follows one individual for two consecutive years. ${ }^{6}$ The rest of the information is at the municipal level and has been linked to IDS data. It comes from a survey of municipalities conducted by the University of Turku, a survey of municipalities conducted by the author, from the Social Insurance Institution of Finland and from Statistics Finland. Aggre-

\footnotetext{
${ }^{6}$ In rotating panel each household is surveyed in two consecutive years and each year half of the sample consists of new households. Thus there are two consecutive observations for each individual.
} 
gated to the municipal level, the data constitute a panel where each municipality can be followed over the years. The main estimation sample includes families whose youngest child is between 9 months and 3 years old. Pooled for all years, there are about 6,000 households in this group and about 14,000 households that have children under the age of 6 . The data contain a rich set of variables describing family characteristics, demographics, incomes and benefits derived from registers and surveys.

Table 2 shows descriptive statistics. It categorizes mothers according to the age of their youngest child. Mothers in the main estimation sample, shown in the first column, are on average 32 years old and have at least high school education almost 50 per cent of the time. The most typical families are those with one or two children, but there are also larger families in the data.

Table 2: Descriptive statistics

\begin{tabular}{|c|c|c|c|c|c|}
\hline & \multicolumn{2}{|c|}{ Youngest child 9 mon. - 2 y. } & \multicolumn{2}{|c|}{ Youngest child 3 - 7 y. } & \\
\hline & Mean & $\mathrm{Sd}$ & Mean & $\mathrm{Sd}$ & \\
\hline Number of obs. & 5709 & & 8411 & & \\
\hline Age & 32.09 & $(5.26)$ & 36.24 & $(5.40)$ & \\
\hline Earned income & 7726 & $(10510)$ & 14983 & $(12979)$ & \\
\hline Employment rate & 0.35 & $(0.48)$ & 0.65 & $(0.48)$ & \\
\hline Education N/A & 0.11 & & 0.12 & & \\
\hline Basic education & 0.42 & & 0.43 & & \\
\hline Higher education & 0.26 & & 0.26 & & \\
\hline Bachelor or higher & 0.21 & & 0.18 & & \\
\hline $\mathrm{N}$ of children under 7 & 1.65 & $(0.70)$ & 1.24 & $(0.45)$ & \\
\hline
\end{tabular}

The main outcome variables are employment status and earned income of a parent that comes from tax registers measured as a sum for the whole calendar year. I construct the employment status using earned income of a parent and a threshold level derived from the earned income of everyone in the data. I define mothers as employed when their annual earned income is higher than half of the annual mean income for women in labour force in the data. ${ }^{7}$ The choice of the threshold is somewhat arbitrary. However, this annual income based measure easily identifies mothers who spend 1 or 2 years outside of labour force, rather than being couple of months

\footnotetext{
${ }^{7}$ More specifically I have measured income from women who are between 20 and 59 years old and not being in sick leave, retired or other ways outside of the labour force.
} 
Figure 6: The distribution of earned incomes divided by education in a group of mothers whose youngest child is between 9 months and 3 years old

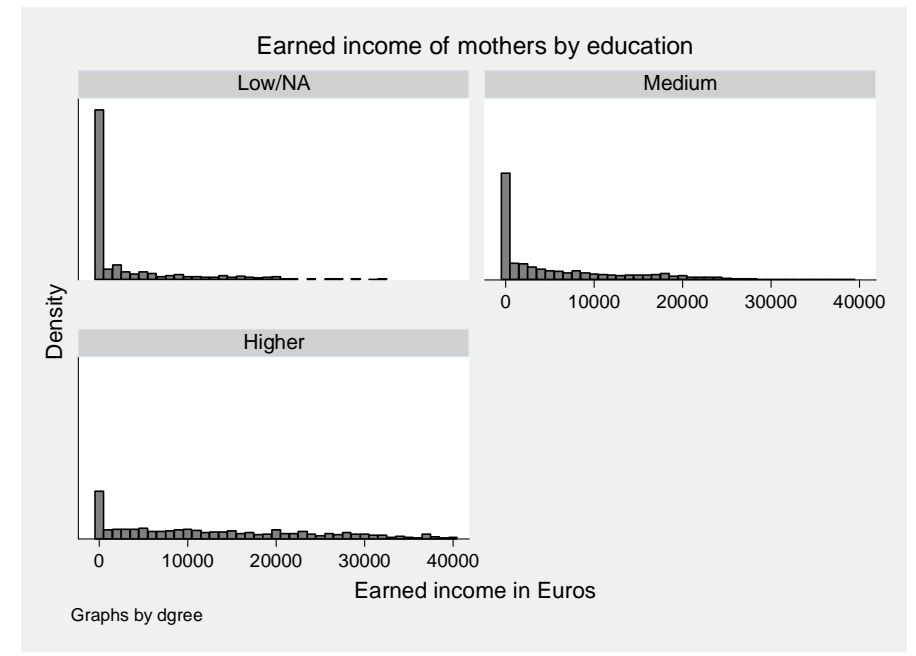

unemployed. Moreover, it is important to note, that the results are not sensitive for the precise selection of employment threshold. This is discussed in more detail in robustness checks after the main estimation results. Putting the employment threshold to zero would not be a good measure of employment. In this case someone who works just one day in a year would be categorized as employed although practically she has not been employed in that year.

Figure 6 shows the actual earned income distribution in the main estimation sample divided into three education categories: low- $^{8}$, medium- ${ }^{9}$ and high-education group ${ }^{10}$. It is evident that fair amount of mothers do not work during the whole calendar year in all groups. The threshold for participating varies by the education category and year. For low educated, the typical mean income calculated for women in the labour force is $15000 €$ per year, leading to employment threshold of $7500 €$ per year. For the high education category the typical mean income is $25000 €$ per year leading to employment threshold of less than $13000 €$ per year. According to Statistics Finland (2011) a woman in full-time employment earned in 2008 about 2500€ per month. This illustrates that someone earning around $10000 €$ per year could not have been in full time employment the whole year.

The explanatory variable in the main estimations is a supplement to the home-care allowance.

\footnotetext{
${ }^{8}$ where education qualification is primary education or the information is missing

${ }^{9}$ where education qualification is secondary education, or post-secondary but not tertiary

${ }^{10}$ where mothers have an educational qualification equivalent to bachelor or higher
} 
The amount of supplement one is eligible for is imputed to everyone in the sample using observable characteristics (family size, age of children and municipality they live in) and based on the eligibility rules. These rules are described in section 2. The main variation in the rules is changes in the amount of supplement and the age limit of the youngest child.

The home-care allowance, day-care fees and family income are implemented for everyone in the data according to policy rules using the predicted income that is estimated based on those in full-time work and controlling for family characteristics. In estimating participation elasticity, the net difference of these variables defines the change in after-tax incomes associated with entry. To make income uncorrelated with actual working status, it is imputed for those not being in work based on observable characteristics and the incomes of those who are in work. Two after-tax incomes are calculated for each family, one corresponds to the mother not being in work and the other to the mother being in work. If there are many children, the scenarios calculated are one where all the children are in home care when mother is not in work, and one where all the children are in public day care when mother is in work.

Figure 7 shows the employment trend of mothers by the age of the youngest child. It is evident how the employment rate of mothers increases with the age of the youngest child. The figure also shows the share of those receiving a municipal supplement relative to all mothers in the sample by the age of the youngest child. It is noticeable how the two lines have opposite slopes. A variable for the age of the youngest child in the estimations captures the correlation of employment of mothers and the age of the youngest child. 
Figure 7: Employment rate of mothers by the age of youngest child and proportion receiving a supplement.

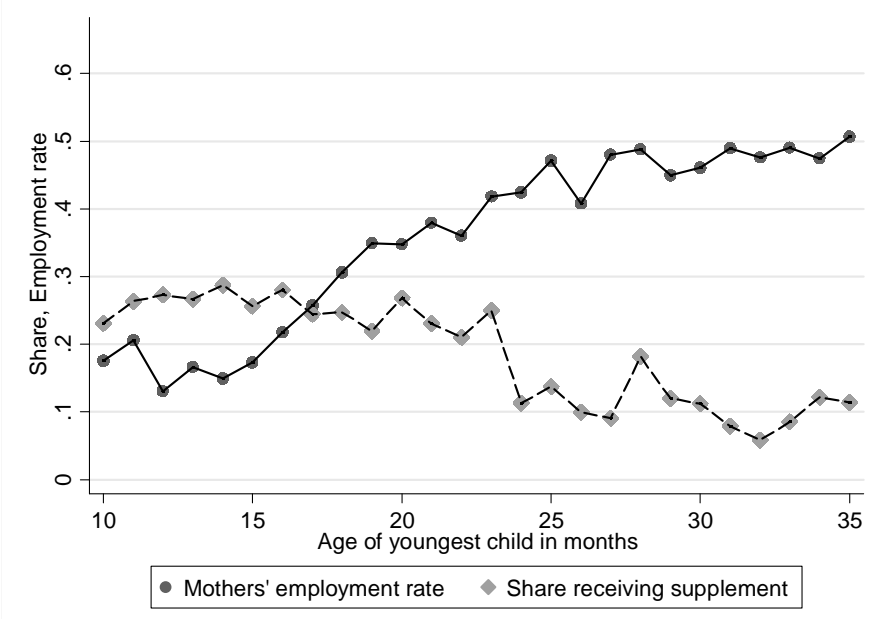

Table 3 shows the mean values, standard deviations and the number of observations of supplement and employment rate. The table contains statistics of mothers whose youngest child is between 9 months and 3 years old for selected years. Table 3 is divided to two parts: the left panel contains everybody in the sample for the year in question, and the right panel contains only those who live in a municipality with a supplement policy in place in the year in question. The second variable from the left, the share receiving supplement, is the share of the whole sample that lives in a municipality that has the supplement policy. It is evident that this figure has increased over time. Over the same time period, the mean amount of supplement parents are eligible for has changed. The average monthly supplement is around 200 euros towards the end of the observation period. Mothers do not on average have a very high participation rate, and this is also reflected in their low gross incomes. From the right panel it is interesting to see that the employment rate and the mean earned income have fallen over time in the group eligible for supplement relative to the whole sample in the left panel. 
Table 3: Outcome and treatment variables

\begin{tabular}{ccccccccc}
\hline & \multicolumn{1}{c}{ All } & \multicolumn{5}{c}{ Cond. on eligible } \\
\hline Year & Supplement, \% & Empl., \% & Income & $\mathrm{N}$ & Supplement, \% & Empl., \% & Income & $\mathrm{N}$ \\
\hline \multirow{2}{*}{1995} & 0.06 & 0.36 & 6305 & 761 & 120 & 0.46 & 7881 & 46 \\
& $(0.24)$ & $(0.48)$ & $(8294)$ & & $(30)$ & $(0.50)$ & $(9754)$ & \\
1999 & 0.17 & 0.37 & 7941 & 693 & 206 & 0.39 & 8491 & 116 \\
& $(0.37)$ & $(0.48)$ & $(10306)$ & & $(83)$ & $(0.49)$ & $(9997)$ & \\
2001 & 0.20 & 0.39 & 8932 & 713 & 212 & 0.35 & 7216 & 145 \\
& $(0.40)$ & $(0.49)$ & $(10554)$ & & $(76)$ & $(0.48)$ & $(8906)$ & \\
2005 & 0.23 & 0.36 & 9466 & 638 & 190 & 0.32 & 7453 & 144 \\
& $(0.42)$ & $(0.48)$ & $(11989)$ & & $(75)$ & $(0.47)$ & $(9374)$ \\
\hline
\end{tabular}

year. The standard deviations are given in italics below the mean values.

\section{$5 \quad$ Estimation results}

\section{Main results}

Table 4 shows the main estimation results. The dependent variables are the mothers' employment dummy and earned income. The monetary variables (such as the municipal supplement and earned income) are in 100 euros per month. I perform all the estimations for fathers as well and find zero effect on their labour supply. 
number of children in the municipality. The results are robust to including or excluding any one or all of these time-varying covariates. Column (iv) presents the triple-difference results. The third difference is between having the youngest child in the age group of 9 months to 2 years or of 3 to 5 years. The latter age group is never entitled to a supplement or the home-care allowance. An advantage of the triple-difference estimate is that it allows controlling for very flexible municipality-specific time trends.

The main result for the employment dummy indicates that increasing the municipal supplement by 100 euros per month causes $3 \%$ fewer mothers to participate. The main result for earned income indicates that increasing the municipal supplement by 100 euros per month decreases the annual income by 1100 euros. ${ }^{11}$ Since there is variation in the way in which mothers respond to the municipal supplement, I interpret these results as the average treatment effect on the treated.

\section{Robustness and sensitivity checks}

To check against spurious specification in the main estimations, I perform robustness checks. First I estimate whether mothers' employment and earned income differ between the treatment and control groups already prior to changes in municipal supplements. More specifically, I take leads and lags from a DD variable, eligibility for $P$ euros of supplement. Top panel of figures 1 and 2 present estimated coefficients for these leads and lags. ${ }^{12}$ The coefficients of lags are zero, whereas the current year estimate and first lead are negative and statistically significant. The zero result from coefficients of lagged policy variables indicate that the policy changes were not implemented due to changes in maternal employment and there were no anticipation effects. It seems that the treatment and control groups behaved in a similar way prior to reforms in supplement policies. Thus, the data seems to behave according to assumptions in natural experimental approach.

I perform further robustness checks in table 5. Column (i) introduces a pseudo-rule that makes mothers whose youngest child is between 3 to 5 years old eligible for the municipal supplement

\footnotetext{
${ }^{11}$ The average net-of-tax income per month for a woman working full time is around $1500 €$ (own calculations).

${ }^{12}$ Some of the municipal supplement rules where simplified in order to be able to take the leads and lags, like fine tuning of sibling extras for supplement. These simplifications do not affect the euro amounts of supplements much, and more importantly, do not delete or create any reforms to the supplement policies. The regression included municipal and year dummies, as well as dummies for every two years of age for youngest child and controls for characteristics of mother.
} 
if they live in a supplement municipality. Families with older children appear natural candidates for performing a robustness check on, since their characteristics should, otherwise than the age, be close to families in the actual treatment group. In reality the mothers in this regression are never eligible for municipal supplement. The estimates are otherwise similar to those in table 4, column (iii) for the employment dummy outcome. The zero result in column (i), table 5 indicates that the result in the main results was not a spurious correlation coming through from different employment shock for all mothers in treatment municipalities. Further, the result implies that supplement policy does not have a delayed effect on mothers' employment. This is in line with OECD (2007) statistics that indicate that the employment of mothers with slightly older than eligible children is much higher than the employment of mothers with children eligible for municipal supplement.

Table 5: Robustness checks

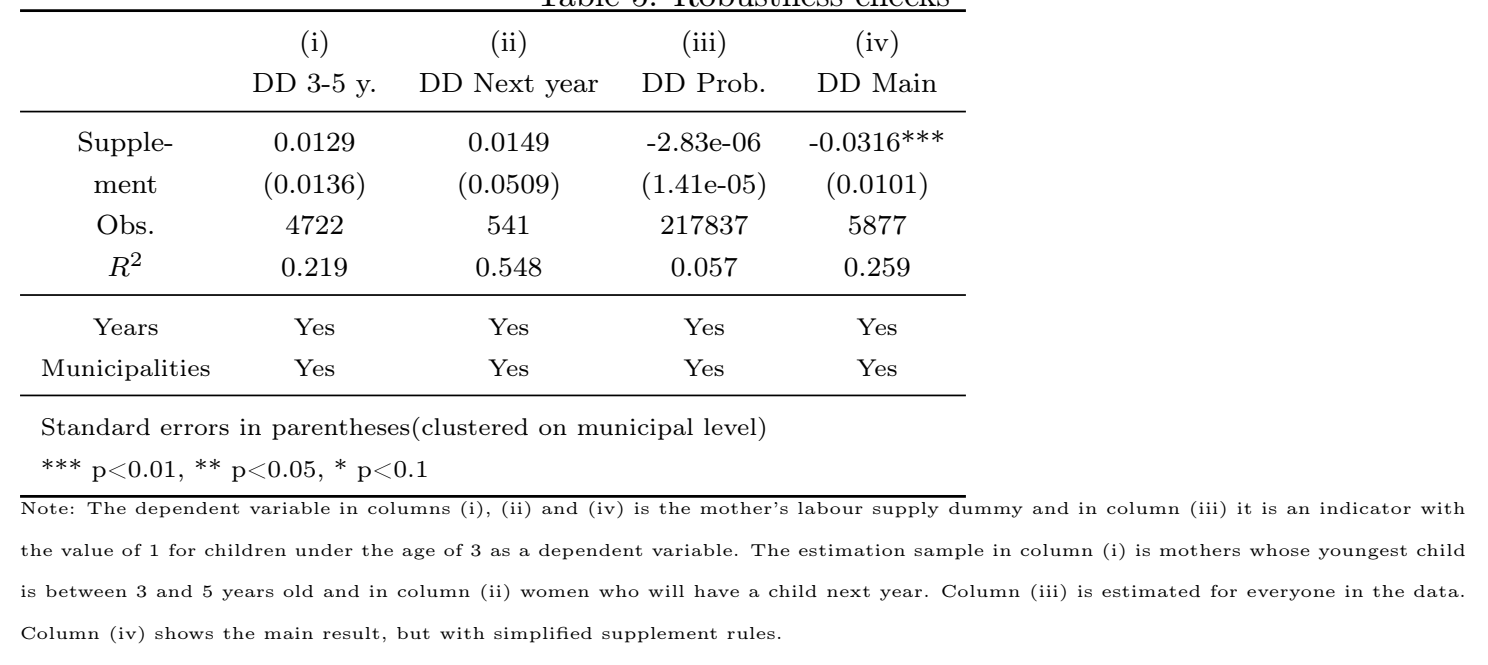

Bottom panels of figures 1 and 2 present the coefficients of leads and lags of the same placebo DD variable as in in column (i), table 5 . It is reassuring for the identification that the coefficients of leads and lags, as well as that of the current year, are all zero. This, together with the first robustness check in the top panel in the same figures, creates confidence that the identification strategy used in main estimates reveals a causal relationship between the supplement policy and maternal labour supply.

Column (ii) of table 5 presents a robustness check for a different group: women who are going 
to have a child the following year. Here I utilize the rotating panel feature of the data, which I do not use elsewhere in the estimations, since this reduces the amount of data to half without significant advantage in the main estimations. The model is estimated for families that will have a child aged 9 months or younger the following year, but do not currently have any children between 9 months and 2 years old. Thus, they are not yet entitled to municipal supplement, but live in municipalities that have the policy. This estimate should tell something about the potential anticipation effect. However, the coefficient of the supplement is zero. This indicates that there is no serious anticipation effect (although the result is imprecise, since the sample size is only 541).

Column (iii) of table 5 presents a robustness check against fertility and parents moving at the same time. It checks if there is a higher probability of ending up in the estimation sample associated with changes in a supplement policy. The outcome is a dummy indicating whether or not a person is a child under three years old (those who are entitled to a supplement). The regression is otherwise similar to main estimates. It checks whether being an eligible child is correlated with changes in municipal supplement. This model is estimated for everyone in the data. The result shows that the supplement does not have any effect on causing children to end up in the estimation sample. Thus families with small children do not move to municipalities offering a supplement, because there was an increase in the supplement. ${ }^{13}$ Moreover, mothers in supplement municipalities do not seem to be more fertile because of changes in the supplement. Column (iv) presents a base-line estimation, but with the simplified rules needed for the implementation of a supplement used in other robustness checks. These simplifications were minor in monetary terms and did not create any new changes to the supplement policies. The coefficient of the municipal supplement is similar to main estimates, and the simplification of rules does not seem to affect the estimates.

As a further sensitivity check, I included to the main estimates as additional covariates a linear time trend for every municipality, used another definition for the employment dummy ${ }^{14}$ and excluded some individual municipalities or years without significant effect to the results.

\footnotetext{
${ }^{13}$ Finnish municipalities are typically large in surface area. Thus, moving to another municipality usually means moving to a completely different city or town.

${ }^{14}$ The other definition is the number of months worked as based on a survey question. The results for this are shown in table A1. There is a measurement error in this variable, thus I did not use it in the main estimates.
} 
Tables A2 and A3 show some of the results. Since the point estimate does not change much when conditioned on municipal-level variables, findings in the main estimates do not seem to depend directly on macroeconomic conditions of the municipalities.

In summary, the main result in column (iv) of table 4 seems to be robust to a quite flexible set of control variables. In effect, once the municipal and year fixed effects are included, the coefficients of the eligibility for $P$ euros of supplement is robust to either including or excluding covariates like mother's or spouse's age or education, spouse's income, municipal unemployment or demographic characteristics and even year by municipality fixed effects. However, it is necessary to control for the age of the youngest child. Since this variable is closely correlated with the employment of mothers, and the treatment is not constant within the age of the youngest child, it turns out to be important to include this covariate, as is done in all applicable estimates.

\section{Divided sample results}

To check for possible variation by sub-groups, I divided the sample according to two predetermined dimensions: the mother's education and the number of children in a family. Thus dividing the sample along these dimensions should not be correlated with treatment effects. Table 6 collects the results. The dependent variable is the mothers' employment dummy in the top panel and earned income in the bottom panel. The supplement is measured in 100 euros per month.

Table 6: Divided sample results

\begin{tabular}{llcccccc}
\hline & Low ed. & Medium ed. & High ed. & 1 child & 2 child & 3 child \\
\hline \multirow{2}{*}{ Work } & \multirow{2}{*}{ Supplement } & $-0.075^{* *}$ & -0.019 & $-0.05^{* *}$ & $-0.05^{* * *}$ & $-0.046^{* * *}$ & 0.030 \\
& & $(0.034)$ & $(0.014)$ & $(0.023)$ & $(0.014)$ & $(0.014)$ & $(0.048)$ \\
& \multirow{2}{*}{ Obs. } & 647 & 3873 & 1189 & 2633 & 2535 & 541 \\
& $R^{2}$ & 0.462 & 0.226 & 0.380 & 0.265 & 0.269 & 0.444 \\
\hline \multirow{2}{*}{ Income } & \multirow{2}{*}{ Supplement } & -773 & -269 & $-2,288^{* * *}$ & $-1,511^{* * *}$ & $-957^{* * *}$ & 223 \\
& \multirow{2}{*}{ Obs. } & $(602)$ & $(234)$ & $(610)$ & $(298)$ & $(318)$ & $(966)$ \\
& \multirow{2}{*}{$R^{2}$} & 3847 & 3888 & 1190 & 2650 & 2535 & 540 \\
\end{tabular}

Standard errors in parentheses (clustered on municipal level)

$* * * \mathrm{p}<0.01, * * \mathrm{p}<0.05, * \mathrm{p}<0.1$

Note: The dependent variable in the top panel is the mothers' labour supply dummy and in the bottom panel the mothers' earned income.

The sample of mothers whose youngest child is between 10 months and 3 years is divided by family size and mother's education. All the estimates were controlled with the same control vector as for the main results and it includes earned income of spouse. 
The divided sample results by education suggest there is an u-shape in response profile: loweducated respond more than medium-educated and the high-educated respond the most. The same overall result arises for both dependent variables, although the earned income coefficient is not statistically significant for low-educated group. ${ }^{15}$ It is intriguing that for the high education group the coefficient is larger than for the medium education group. This is interesting because education is usually highly positively correlated with incomes, which figure 6 confirms in the present case. The result suggests that mothers who have high income potential respond more to changes in taxation than mothers who have medium income potential.

On potential worry is that the $\mathrm{u}$-shape result by education has something to do with educational attainment directly and not the apparent correlation with education and income. I cannot test against this directly, since I do not observe mothers' income prior to having children. One argument against this worry is that it does not seem likely that many mothers would still be studying, since they are on average older than a typical student. Another argument is that the education fields are not systematically correlated with education level. For example, in public sector areas it might be easier to stay at home for prolonged periods, but there are public sector workers in all education level groups. Finally, all the results are controlled for spouses income. Therefore the explanation for the u-shape does not seem to be that higher educated mothers have wealthier husbands.

In the previous literature, there are few attempts to estimate labour supply responses across income or education groups. Eissa (1995) studied labour supply effects of The Tax Reform Act of 1986 on married women in the second top income percentile. She found overall labour supply elasticity of 0.8. In comparison, Eissa and Liebman (1996) found a larger estimate for their lower education group than for higher education group. Since the municipal supplement it does not depend on income prior to having the child, the amount a mother is eligible for does not depend on the education or income she has. Thus this divided sample result contributes to the literature by being a good way to analyse participation responses across education levels.

It is also interesting that the result divided sample result by family size in table 6 is much stronger for families with 1 or 2 children than for larger families. The statistically insignificant

\footnotetext{
${ }^{15}$ For participation essentially the same set of results came out when the participation threshold was defined as $30 \%$ of mean income of the education group.
} 
result for larger families partly reflect their low number in the data, but the zero coefficient is still suggesting that larger families do not respond that much to the supplement policies as smaller families. This result is interesting because it suggests that the mothers' participation elasticity profile is non-linear in the number of children she has.

\section{Participation elasticity}

This section provides participation elasticity estimates that are important for putting the main estimates into a policy-relevant context. Participation elasticity puts the participation effect into the context of prevailing employment rates and benefit and income levels. Furthermore, optimal income tax models that take the extensive margin into account, employs the inverse of participation elasticity (Saez 2002).

To estimate the participation elasticity, I need to estimate the net after-tax income associated with participation for everybody. For this, I impute two income measures for every mother. The first measures the after-tax income of non-employed mother (who takes care of her children at home) and the second measures the after-tax income of employed mother (who puts the children into public day care). The income measures that corresponds to these two choices are shown in equations (1) and (2). The net after-tax participation income is calculated by taking the difference of these two measures. I need to make assumptions to be able to impute these two measures. One assumption is that non-employed mother always takes care of her children at home and employed mother always puts her children at public kindergarten. In reality there are more choices available, private day care, for example. Another assumption is that spouses do not make joint employment decisions.

I simulate the two income measures, since only one of the two states is observed in any data. This is the standard missing counterfactual problem. I follow the typical solution to recover the counterfactual income measure. I associate parents' income with the income in the counterfactual state based on predetermined characteristics. Thus for employed status, I impute the income based on the average net income of employed mothers who have the same education and age class and live in the same broader region. For non-employed mothers' transfers from the government I use similar procedure and also the home-care allowance rules that I observe. 
The difference in the two incomes corresponding to the two employment status is the participation income. This measure is endogenous to participation decision in the participation regression, since it is calculated based on mothers who have self-selected into employment and non-employment. Therefore I use the municipal supplement as an instrument for participation income when estimating the effect of participation income on participation status. The various robustness checks presented in the previous section contribute to validating the use of this instrument. To be a good instrument, changes in the municipal supplement policies should not be correlated with unobserved factors in participation regression.

The results are shown in table 7 . The explanatory variable is a dummy for participation status as in the main estimates. Now the unit of measurement is 1 euro per year. The first stage, shown in the first line, is very strong. There is almost a one-to-one relationship between the participation income and the amount of supplement one is eligible for. The second stage results from 2SLS implies that 1 additional euro in participation income leads to an increase in participation probability of $.003 \%$.

Table 7: Change in mothers participation in response to change in incomes

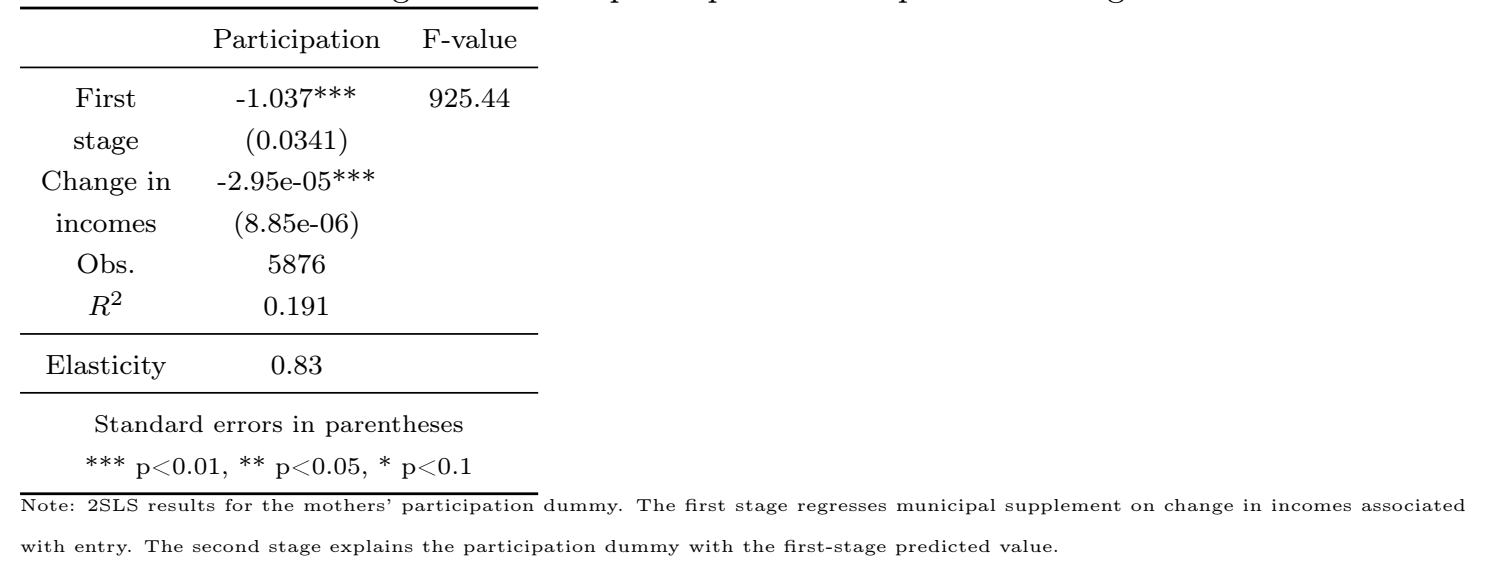

The participation elasticity $(\eta)$ implied by the coefficient in the table 7 can be calculated as

$$
\eta=\frac{\text { dparticipation }}{\text { dincome }} * \frac{\text { income }}{\text { participation }}=
$$




$$
\beta * \frac{\text { income }}{\text { participation }}=0.0000295 *((9814) /(0.348))=0.83
$$

where $\beta$ refers to the coefficient of participation income in the second stage regression. The above elasticity is calculated on an annual basis. The 9814 euros, the income, is the average change in net income associated with labour market entry for a typical mother. The 0.348 , the participation, is the average participation rate in the population for which the estimation was made.

Table 8 shows the participation effect by education level. The result is larger than the average result and statistically significant for mothers with low or missing education and for mothers with a bachelor degree or higher. The participation elasticities implied by these estimates for low, medium and high education levels are $0.000038 *(7050 / 0.2)=1.3,0.000017 *(8060 / 0.35)=0.4$ and $0.000038 *(17470 / 0.44)=1.5$, respectively. These participation elasticities confirm the $\mathrm{u}-$ shape profile of participation elasticities by education suggested by the reduced-form divided sample results. Higher educated respond to financial incentives more than medium educated even when accounting for their higher than average income.

Table 8: Participation response by mothers education

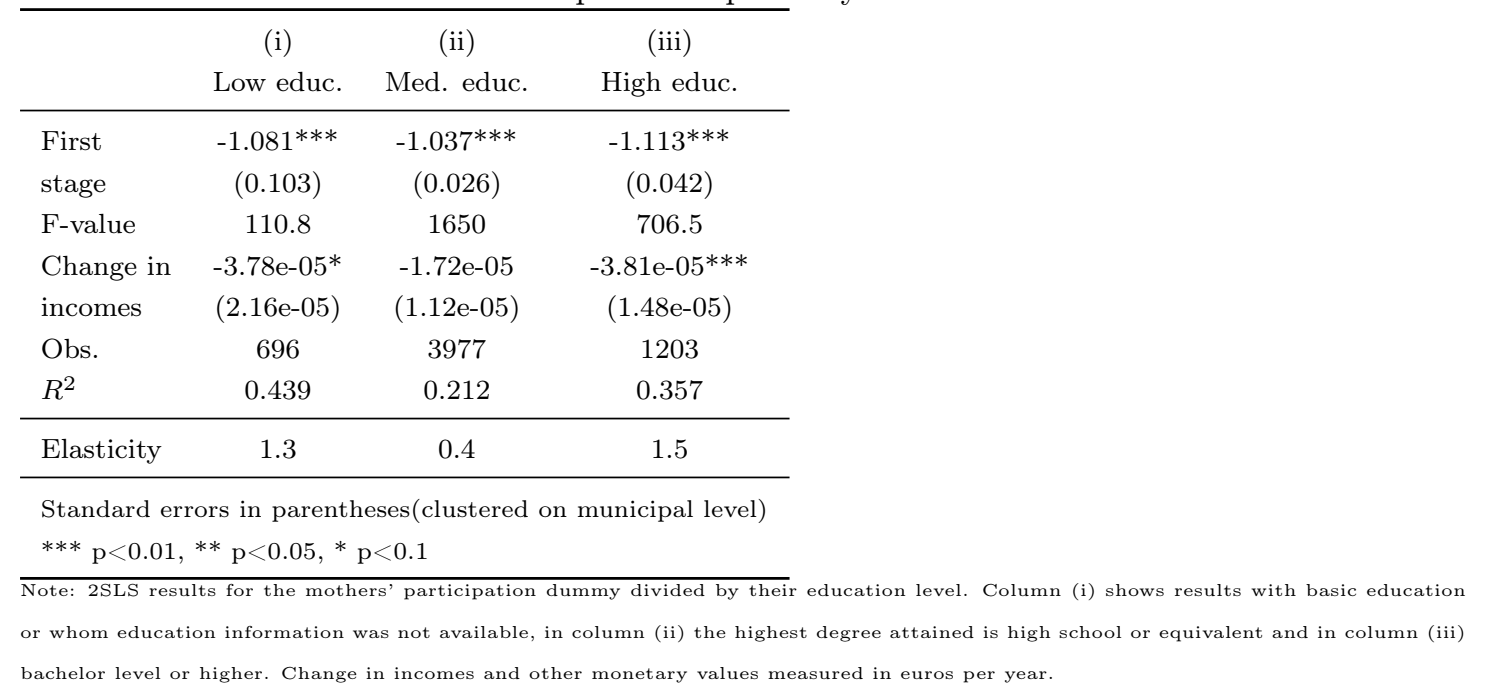

Although I needed to make a number of assumptions, the reduced form estimate here is 
performed more carefully here than in some earlier studies analysing the effect of child-care benefits on labour supply (Baker et al. 2008 and Milligan and Stabile 2007). Here I take the change in net after-tax income associated with entry explicitly into account with the instrumental variable procedure. This is possible since supplements do not directly depend on income. To report some earlier estimates in the literature, Baker et al. (2008) estimated a participation elasticity of 0.236 resulting from decreasing child-care cost, and Milligan and Stabile (2007) reported an elasticity of 0.96 for having earnings as a major source of income utilising the Canadian benefit reform. Eissa and Liebman (1996) estimated a participation elasticity of 0.6 for single mothers.

\section{Conclusion}

This paper presents evidence on the extent to which child-care benefits affect parental labour supply. An important component of this study is a particular feature of the Finnish child-care system: a municipal supplement to the child home-care allowance (HCA). This provides plausibly exogenous variation in the labour supply incentives of mothers. To be entitled to the HCA a parent needs to stay at home taking care of children who are younger than three years old. Some municipalities pay supplement to the HCA. The average supplement is 150 euros per month.

I found a very robust result that a municipal supplement to the home-care allowance has a negative effect on maternal labour supply. The main estimate indicated that increasing a municipal supplement by 100 euros per month causes 3 per cent fewer women to participate. However, I did not find any effect on the labour supply of fathers who are also eligible for the home-care allowance. Furthermore the results indicate that when the home-care allowance period ends, mothers return to employment. Thus the policy does not seem to have a delayed effect on employment.

Strength in analysing the Finnish municipal supplement system is that it affects income of an individual who is not participating to labour force. The alternative is a reform in day care fees or means tested benefits that affect income when participating to labour force. Income related benefits typically depend on wage rate that is associated with unobserved ability, which leads to potential endogeneity problem. On the contrary, this problem disappears when the variation 
is not dependent with wage rate, such as in the municipal supplement system. Therefore the municipal supplement affects the labour force participation incentives clearly in an exogenous way.

Utilising this feature, I put the results into a broader policy context by estimating the participation elasticity. This estimation takes into account the participation income defined as the difference in income when a parent is non-employed and when employed. This essentially describes how much more income a parent earns when participating to labour. I then calculated the proportional variation in benefits to participation income. Estimating the causal effect of this proportional variation on parental labour supply is possible since municipal supplements are clearly exogenous to participation decisions of parents. The result implied a participation elasticity of around 0.8. This estimate is towards the high end of the range of elasticities found in other studies (Baker and Milligan 2008b, Lefebvre and Merrigan 2008 and Milligan and Stabile 2007).

When studying labour supply decisions, it is important to contrast the size of the benefit to the available income when a parent is employed. Other papers analysing Nordic child care institutions found very small effect on maternal employment (Havnes and Mogstad 2011a and Lundin et al. 2008). It is possible that the variation in participation income was not as great as it is in the Finnish HCA system, and that it is important whether the policy studied targets parents who are employed or non-employed. Moreover, Schone (2004) and Naz (2004) study Norwegian Cash-For-Care (CFC) reform similar to the HCA studied here in that it also applies to families staying at home taking care of their children. They found larger effect on parental labour supply than the other papers studying the Nordic child care systems, but a smaller affect than what I found here. The key difference between CFC and HCA systems is that the former applies to everybody who do not have their children in public day care, while the latter is tied to a parent staying at home and taking care for his or her own children. Thus the HCA system has much larger impact on labour supply incentives than the CFC system.

For the above mentioned reasons the relatively large participation elasticity found here makes an important contribution to literature. Home-care related policies do seem to matter, when it is clear that the variation in policy is sizeable compared with an alternative income available to parents. Thus countries thinking about reforming their child-care policies should take into 
consideration that increasing benefits related non-employment could lead to significant parental labour supply responses.

\section{References}

[1] Baker, M., Gruber, J. and Milligan, K., 2008a: Universal Child care, Maternal Labour Supply and Family Well-being. Journal of Political Economy 2008, Vol. 116, no. 4 .

[2] Baker, M. and Milligan, K., 2008b: How Does Job-Protected Maternity Leave Affect Mothers' Employment? Journal of Labour Economics 2008, Vol. 26, no. 4.

[3] Baker, M. and Milligan, K., 2010: Evidence from Maternity Leave Expansions of the Impact of Maternal Care on Early Child Development. Journal of Human Resources, Vol. 45, No. 1, pp. 1-32.

[4] Bertrand, M., Duflo, E. and Mullainathan, S., 2004: How Much Should We Trust Differences-in-Differences Estimates? Quarterly Journal of Economics February 2004, Vol. 119, No. 1: 249-275.

[5] Blau, D., 2003: Child care subsidy programs. Working Paper no. 7806, National Bureau of Economic Research, Cambridge, MA. Reprinted in Robert Moffitt, ed.: Means-tested transfer programs in the United States, Chicago: University of Chicago Press.

[6] Blau, D. and Robins, P., 1988: Child-Care Costs and Family Labour Supply. Review of Economics and Statistics 70: 374-381.

[7] Blundell, R., Brewer, M. and Shephard, A., 2005: Evaluating the labour market impact of Working Families' Tax Credit using difference-in-differences. Institute for Fiscal Studies, Externally published reports, June 2005.

[8] Blundell, R., Duncan, A., McCrae, J. and Meghir, C., 2000: The Labour Market Impact of the Working Families' Tax Credit. Fiscal Studies vol. 21, no. 1, pp. 75-104. 
[9] Blundell, R., Duncan, A. and Meghir, C., 1998: Estimating Labor Supply Responses Using Tax Reforms. Econometrica, Vol. 66, No. 4 (Jul., 1998), pp. 827-861.

[10] Blundell, R. and Macurdy, T., 1999: Labor supply: A review of alternative approaches. Handbook of Labor Economics, in: O. Ashenfelter \& D. Card (ed.), Handbook of Labor Economics, edition 1, volume 3, chapter 27, pages 1559-1695 Elsevier.

[11] Brewer, M., Duncan, A., Shephard, A. and Suaréz, M., 2006: Did working fmailies' tax credit work? The impact of in-work support on labour supply in Great Britain. Labour Economics, 13, pp. 699-720.

[12] Card, D. and Levine, P., 2000: Extended benefits and the duration of UI spells: evidence from the New Jersey extended benefit program. Journal of Public Economics 78 , pages $107-138$.

[13] Cascio, E., 2009: Maternal Labor Supply and the Introduction of Kindergartens into American Public Schools. Journal of Human Resources. Vol. 44, No. 1.

[14] European Commission, 2007: Ten years of the European Employment Strategy (EES). Directorate-General for Employment, Social Affairs and Equal Opportunities, Unit D.2.

[15] Eissa, N. 1995: Taxation and Labor Supply of Married Women: The Tax Reform Act of 1986 As a Natural Experiment. NBER Working Paper 5023.

[16] Eissa, N. and Hoynes, H., 2004: Taxes and the labor market participation of married couples: the earned income tax credit. Journal of Public Economics, 88, pp. 19311958.

[17] Eissa, N. and Liebman, J., 1996: Labor Supply Response to the Earned Income Tax Credit. Quarterly Journal of Economics, Vol. 111, No. 2 (May, 1996), pp. 605-637.

[18] Fitzpatrick, 2010: Preschoolers Enrolled and Mothers at Work? The Effects of Universal Prekindergarten. Journal of Labor Economics, Vol. 28, No. 1. 
[19] Fitzpatrick, 2012: Revisiting Our Thinking About the Relationship Between Maternal Labour Supply and Preschool. Journal of Human Resources, Vol. 47, no. 3.

[20] Havnes, T. and Mogstad, M., 2011a: Money for Nothing? Universal Child Care and Maternal Employment. Journal of Public Economics 95, 1455-1465

[21] Havnes, T. and Mogstad, M., 2011b: No Child Left Behind: Subsidized Child Care and Children's Long-Run Outcomes. American Economic Journal Economic Policy, Vol. 3, No. 2 .

[22] Immervoll, H., Kleven, H., Kreiner, C. and Saez, E., 2007: Welfare Reform in European Countries: A Microsimulation Analysis. Economic Journal, 117 (January), $1-44$.

[23] Laine V. and Uusitalo, R., 2001: Kannustinloukku-uudistuksen vaikutukset työvoiman tarjontaan. VATT Research Reports 74, Helsinki.

[24] Lalive, R. and Zweimuller, J., 2004: Benefit entitlement and unemployment duration. The role of policy endogeneity. Journal of Public Economics 88, pages 25872616.

[25] Lefebvre, P. and Merrigan, P., 2008: Child-Care Policy and the Labour Supply of Mothers with Young Children: A Natural Experiment from Canada. Journal of Labour Economics, 2008, vol. 26, no.3.

[26] Lindbeck, A. and Persson, M., 2003: The Gains from Pension Reform. Journal of Economic Literature, American Economic Association, vol. 41(1), pages 74-112, March.

[27] Lundin, D., Mörk, E. and Öckert, B., 2008: How far can reduced childcare prices push female labour supply? Labour Economics, vol. 15(4), pages 647-659, August, Elsevier B.V. 
[28] Milligan, K. and Stabile, M., 2007: The integration of child tax credits and welfare: Evidence from the Canadian National Child Benefit program. Journal of Public Economics, Elsevier, vol. 91(1-2), pages 305-326, February.

[29] Naz, G., 2004: The impact of cash-benefit reform on parents' labour force participation. Journal of Population Economics 17:369-383.

[30] OECD, 2005a: Babies and Bosses - Reconciling Work and Family Life (Vol. 4): Canada, Finland, Sweden and the United Kingdom (2005).

[31] OECD, 2005b: Society at a Glance: OECD Social Indicators 2005 Edition. OECD, Volume 2005, Number 2, March 2005.

[32] OECD, 2007: Babies and bosses: Reconciling work and family life. OECD, 2007.

[33] OECD, 2009: Pensions at a Glance 2009: Retirement-Income Systems in OECD Countries.

[34] Saez, E., 2001: Using Elasticities to Derive Optimal Income Tax Rates. Review of Economic Studies, Vol. 68, No. 1 (Jan., 2001), pp. 205-229.

[35] Saez, E., 2002: Optimal Income Transfer Programs: Intensive versus Extensive Labor Supply Responses. Quarterly Journal of Economics, Vol. 117, No. 3, (Aug., 2002), pp. 1039-1073, MIT Press.

[36] Schone, P., 2004: Labour supply effects of a cash-for-care subsidy. Journal of Population Economics, 2004, vol. 17.

[37] Statistics Finland 2011: National Accounts, Total earnings by employer sector and gender, 2008. Read from http://www.stat.fi/tup/suoluk/suoluk_palkat_en.html in 24 February, 2011.

[38] Viitanen, T., 2007: Childcare voucher and labour market behaviour: Experimental evidence from Finland. Sheffield Economic Research Paper Series, SERP Number: 2007011, United Kingdom. 


\section{A Appendix: Further robustness and sensitivity checks}

Table A1 reports estimates based on an outcome variable where mothers have reported working 10 or more months in an interview. Column (iii) reports a DD estimate equivalent to the main estimates. Although the coefficient is smaller, it implies a similar participation elasticity, since the participation elasticity measured in this way is smaller than in normal estimates.

Table A1: Estimations with work dummy based on survey question

\begin{tabular}{lccc}
\hline & (i) & (ii) & (iii) \\
\hline Supplement & $-0.055^{* * *}$ & $-0.084^{* * *}$ & $-0.014^{*}$ \\
& $(0.0062)$ & $(0.0096)$ & $(0.0083)$ \\
Years & No & Yes & Yes \\
Municipalities & No & Yes & Yes \\
Child age & & No & Yes \\
Obs. & 6023 & 6023 & 6023 \\
$R^{2}$ & 0.013 & 0.139 & 0.273 \\
\hline
\end{tabular}

Standard errors in parentheses(clustered on municipal level)

$* * * \mathrm{p}<0.01, * * \mathrm{p}<0.05, * \mathrm{p}<0.1$

Note: OLS estimates for the mothers' labour supply dummy with a value of 1 when reported working 10 or more months per year in a survey. Supplement measured in 100 euros per month.

Table A2: Sensitivity checks

\begin{tabular}{llcccccc}
\hline Outcome & Var & (i) & (ii) & (iii) & (iv) & (v) & (vi) \\
\hline Partici- & Supple- & $-0.026^{*}$ & $-0.042^{* *}$ & $-0.026^{*}$ & $-0.030^{* *}$ & $-0.036^{* * *}$ & $-0.027^{* * *}$ \\
pation & ment & $(0.013)$ & $(0.021)$ & $(0.013)$ & $(0.013)$ & $(0.0094)$ & $(0.010)$ \\
& Obs. & 5,709 & 3,572 & 4,493 & 5,273 & 5,709 & 5,709 \\
& $R^{2}$ & 0.225 & 0.245 & 0.223 & 0.206 & 0.206 & 0.203 \\
\hline \multirow{2}{*}{ Income } & Supple- & $-974^{* * *}$ & $-1,133^{* * *}$ & $-861^{* *}$ & $-693^{* * *}$ & & \\
& ment & $(342)$ & $(423)$ & $(361)$ & $(233)$ & & \\
& Obs. & 5,725 & 3,581 & 4,506 & 5,289 & & \\
& $R^{2}$ & 0.325 & 0.350 & 0.321 & 0.313 & & \\
\hline
\end{tabular}

Standard errors in parentheses(clustered on municipal level)

$* * * \mathrm{p}<0.01, * * \mathrm{p}<0.05, * \mathrm{p}<0.1$

Note: OLS estimates for the mothers' labour supply dummy and earned income. Supplement measured in 100 euros per month. Column

(i) includes linear municipal trends where some smaller municipalities were grouped together. Column (ii) includes only years from 1995 to 2001 and column (iii) only years from 1998 to 2005. Column (iv) leaves out the largest municipality in the sample. Column (v) sets the employment threshold to 70 per cent of the mean income and column (vi) sets the threshold to 30 per cent of the mean income. 
Table A3: Sensitivity check: results for fathers

\begin{tabular}{llcc}
\hline Outcome & Coefficient & (i) & (ii) \\
\hline Work & Supplement & 0.0026 & 0.0043 \\
& & $(0.0093)$ & $(0.0095)$ \\
& Obs. & 5527 & 5527 \\
& $R^{2}$ & 0.197 & 0.224 \\
\hline \multirow{2}{*}{ Income } & Supplement & 244 & -91 \\
& & $(279)$ & $(262)$ \\
& Obs. & 5560 & 5560 \\
& $R^{2}$ & 0.366 & 0.387 \\
\hline
\end{tabular}

Standard errors in parentheses(clustered on municipal level)

${ }^{* * *} \mathrm{p}<0.01,{ }^{* *} \mathrm{p}<0.05,{ }^{*} \mathrm{p}<0.1$

Note: OLS estimates for fathers' labour supply dummy and earned income. Supplement measured in 100 euros per month. Column (i) is similar to the main DD estimates for mothers. Column (ii) adds linear municipality trends to this. 